\title{
Or. 1807
}
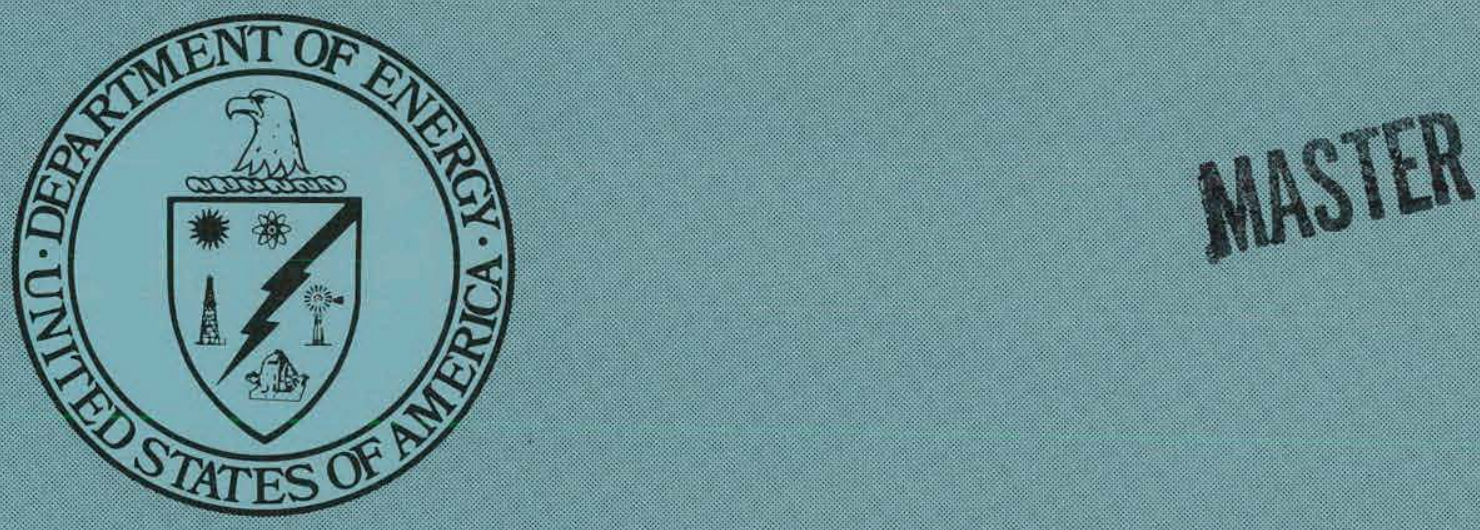

D0E/LETC-1761-2/1

Distribution Category UC-91

ANALYSIS OF REVERSE COMBUSTION IN TAR SANDS:

A ONE-DIMENSIONAL MODEL

By

A. Amr

August, 1980

Work Performed Under Contract No. ET-78-C-03-1761

University of Wyoming

Laramie, Wyoming 82071 


\section{DISCLAIMER}

This report was prepared as an account of work sponsored by an agency of the United States Government. Neither the United States Government nor any agency Thereof, nor any of their employees, makes any warranty, express or implied, or assumes any legal liability or responsibility for the accuracy, completeness, or usefulness of any information, apparatus, product, or process disclosed, or represents that its use would not infringe privately owned rights. Reference herein to any specific commercial product, process, or service by trade name, trademark, manufacturer, or otherwise does not necessarily constitute or imply its endorsement, recommendation, or favoring by the United States Government or any agency thereof. The views and opinions of authors expressed herein do not necessarily state or reflect those of the United States Government or any agency thereof. 


\section{DISCLAIMER}

Portions of this document may be illegible in electronic image products. Images are produced from the best available original document. 


\section{DISCLAIMER}

"This book was prepared as an account of work sponsored by an agency of the United States Government. Neither the United States Government nor any agency thereof, nor any of their employees, makes any warranty, express or implied, or assumes any legal liability or responsibility for the accuracy, completeness, or usefulness of any information, apparatus, product, or process disclosed, or represents that its use would not infringe privately owned rights. Reference herein lu any specific commercial product, process, or service by trade name, trademark, manufacturer, or otherwise, does not necessarily constitute or imply its endorsement, recommendation, or favoring by the United States Government or any agency thereof. The views and opinions of authors expressed herein do not necessarily state or reflect those of the United States Government or any agency thereof."

This report has been reproduced directly from the best available copy.

Available from the National Technical Information Service, U. S. Department of Commerce, Springfield, Virginia 22161.

Price: Paper Copy $\$ 6.00$

Microfiche $\$ 3.50$ 
TABLE OF CONTENTS

Section

Page

Abstract... . . . . . . . . . . . . . . . 1

Nomenclature ..................... 2

1. Introduction ...................... 3

2. Mathemat1cal Model . . . . . . . . . . . . . . 5

3. Numerical Studies .. . . . . . . . . . . . 8

4. Results and Conclustons . . . . . . . . . . . . . . 9

5. Acknowledgments . . . . . . . . . . . . . . 11

Blblolgraphy . . . . . . . . . . . . . . . . 14

Captions for Figures that Follow . . . . . . . . . . 15

Append1x A - One Dimensionsl Reverse Combustion Program "COMBU" 22

Append1x B - Listing of Program "COMBU" . . . . . . . . . . 28

Append1x C - A Sample Computer Printout . . . . . . . . 36 
This paper describes a one-dimensional numerical model which simulates oil recovery from tar sands by reverse combustion. The method of lines is used to solve the nonlinear differential equations describing the flow. The effects of volumetric air flux on the peak temperature, flame velocity, and oil recovery efficiency are reported. The results are compared to the results of relevant experimental studies. 
NOMENCLATURE

$A_{1}=$ Arrhenius constant for oxygen reaction rate, $\mathrm{kg} / \mathrm{m}^{3} \mathrm{hr}$

$A_{2}=$ Arrhenius constant for pyrolysis rate, $\mathrm{kg} / \mathrm{m}^{3} \mathrm{hr}$

$c=$ Specific heat, $\mathrm{kJ} / \mathrm{kg} \mathrm{K}$

$D=$ Effective diffusion coefficient, $\mathrm{m}^{2} / \mathrm{hr}$

$E_{1}=$ Activation energy for oxygen reaction rate, $\mathrm{K}$

$E_{2}=$ Activation energy for pyrolysis rate, $\mathrm{K}$

$\mathrm{H}=$ Heat released per $\mathrm{kg}$ of oxygen consumed, $\mathrm{kJ} / \mathrm{kg}$

$\mathrm{K}=$ Effective thermal conductivity, $\mathrm{kJ} / \mathrm{hr}-\mathrm{m} \cdot \mathrm{K}$

$\mathrm{m}_{\mathrm{a}}=$ Mass flux of air at inlet, $\mathrm{kg} / \mathrm{m}^{2} \mathrm{hr}$

$\mathrm{m}_{\mathrm{g}}=$ Mass flux of gas, $\mathrm{kg} / \mathrm{m}^{2} \mathrm{hr}$

$M_{0}=$ Original bitumen in place, $\mathrm{kg} / \mathrm{m}^{3}$

$\mathrm{N}$ = Weight fraction, nondimensional

$\mathrm{P}=$ Production (pyrolysis) rate of oil $\mathrm{kg} / \mathrm{m}^{3} \mathrm{hr}$

$\mathrm{R}=$ Reaction rate (oxygen), $\mathrm{kg} / \mathrm{m}^{3} \mathrm{hr}$

$\mathrm{t}=\mathrm{Time}$

$\mathrm{T}=$ Temperature, $\mathrm{K}$

$\mathrm{W}=$ Percentage of bitumen in place, nondimensional

$\mathrm{V}=$ Combustion zone velocity, $\mathrm{m} / \mathrm{hr}$

Greek Symbols

$\phi=$ Porosity, nondimensional

$\gamma=$ stoichometric coefficient, nondimensional

$\rho=\operatorname{density}, \mathrm{kg} / \mathrm{m}^{3}$

Subscripts

g = gas

$i=i^{\text {th }}$ species (oxygen: $1=1$, oil: $i=2$ )

$s=$ solid 


\section{Introduction}

It has been estimated that up to thirty billion barrels of oil are contained in tar sand deposits in five states (California, Kentucky, New Mexico, Texas, and Utah) [1]. The deposits in Utah alone are estimated to contain twenty-eight billion barrels of oil.

The U. S. Department of Energy's (DOE) Laramie Energy Technology Center (LETC) initiated a program in 1971 to develop in situ thermal techniques for recovery of oi.l from U. S. tar sand deposits. In situ thermal recovery techniques include steam stimulation ("huff and puff"), steam flooding, forward combustion (fire-flooding), reverse combustion, and fire-water flooding (Cofcaw). These techniques have been utilized successfully in enhanced oil recovery and may be suitable for heavy viscous bitumen found in tar sands.

In forward and reverse combustion, air is injected into the formation. The reaction between the oxygen in the air and the coke (in case of forward combustion) and/or a portion of the oil (in case of reverse combustion) produces the heat necessary for viscosity reduction and oil cracking. The air drive produces the necessary pressure gradient to displace the distilled oil and oil vapor, products of combustion, and connate water towards the production well. In forward combustion, the flame front moves in the same direction as the air flow. 0il flow in the colder region ahead of the flame could result in a plugged flow due to the increased oil viscosity in this region. In reverse combustion, such a problem is avoided. The flame front moves in the opposite direction of air flow and oil flows through the heated region towards the produrtinn we11s. 
Theoretical investigations of reverse combustion in tar sands have been relatively scarce. Four major works in this area have been identified; namely, models developed b.y Berry and Parrish:[2], Warren, Reed, and Price. [3], Kotowski and Gunn [4], and Land [5].. These models were examined as a starting point for our numerical investigation of reverse combustion in tar sands.

AlI four models are one-dimensional and assume a quasi-steady state. The latter assumption implies that the temperature and concentration profiles are unchanged with respect to a coordinate system moving with the constant combustion zone velocity. These models solve the energy balance and mass balance equation in order to obtain temperature and concentration profiles together with combustion zone velocity.

The energy equation is given by

$$
\frac{d}{d x} k \frac{d T}{d x}-\frac{d}{d x}\left(\left(m_{g} c_{g}+V\left(\rho_{s} c_{s}+\phi_{g} \rho_{g} c_{g}\right)\right) T\right)+\phi_{g} H R=0
$$

The conservation of the $i^{\text {th }}$ species is given by

$$
\frac{d}{d x} \rho D \frac{d N i}{d x}-\frac{d}{d x}\left(\left(m_{g}+V_{\phi} \rho_{g}\right) N_{i}\right)+P_{i}-\phi_{g} \gamma_{i} R=0
$$

The dependent variables in equation (1) and (2) are the temperature and the species concentration. All other properties are known except the combustion zone velocity (V). These equations are nonlinear and are coupled through the dependence of the reaction rate on both temperature and concentrations. An additional equation is needed which relates the gas flux with combustion zone velocity and peak temperature. This additional equation is obtained from global heat balance. In such formulation the combustion zone velocity may be considered an eigen-value of the problem. 
Berry and Parrish [2] and Land [5] neglected the diffusion term in equation (2) and considered only the oxygen balance. Furthermore, they assumed a reaction rate which is independent of oxygen concentration. The latter assumption decouples equation (1) from equation (2): Berry and Parrish added a heat loss term to the energy equation.

Warren et. al. [3] included the diffusion term in their model and examined the dependence of the reaction rate on oxygen concentration. Al1 three investigators assumed constant physical properties.

The above mentioned models could be used to estimate the effects of air flux on both the combustion zone velocity and the peak temperature. These results are found to agree satisfactorily with the results of adiabatic tube runs. These models, however, cannot predict either the oil production rate or recovery efficiency. This is because none of the models included an oil mass balance in their analysis.

The model of Kotowski and Gunn was developed to examine the underground coal gasification process. This model is by far the most general of the four available models and includes the effects of variation of physical properties with temperature. It also solves a fuel mass balance in addition to the oxygen balance and energy balance. The Kotowski-Gunn Model predicts the gas production rate, peak temperature, and combustion zone velocity.

\section{IT. Mathematical Model}

A one-dimensional unsteady state model, which simulates reverse combustion in tar sands, is described in this section. The model simulates a reverse combustion experiment similar to the tube runs described by Land [6] and Reed et.al. [7]. In such experlunents; a tube 
was packed with tar sands and was heated at one end while air was injected at a constant flow rate at the other end. When ignition was initiated, heating was stopped and a flame front propagating downstream was observed. Heat losses during the run were prevented by the use of perimeter heating to reduce temperature gradients in the radial direction. A model which describes such experiments consists of a system of four coupled partial differential equations. which result from energy and mass conservation laws and kinetic data. These equations are summarized below.

Energy Equation

$$
\left(\rho_{s} c_{s}+\phi_{g} \rho_{g} c_{g}\right) \frac{\partial T}{\partial t}=K \frac{\partial^{2} T}{\partial x^{2}}-m_{g} c_{g} \frac{\partial T}{\partial x}+\phi_{g} H R
$$

Oxygen Concentration Equation

$$
\phi_{g} \rho \frac{\partial N_{1}}{\partial t}=-m_{g} \frac{\partial N_{1}}{\partial x}-\phi_{g} R-N_{1} P
$$

Oil Vapor Concentration Equation

$$
\phi_{g}^{\rho} \frac{\partial N_{2}}{\partial t}=-m_{g} \frac{\partial N_{2}}{\partial x}-\gamma \dot{g} R+P\left(1-N_{2}\right)
$$

\section{Oil Pyrolysis Rate}

$$
M_{0} \frac{d W}{d t}=P
$$

The subscripts 1 and 2 refer to oxygen and oil respectively.

In deriving the above equations, the following assumptions have been made.

(1) Porosity, specific heats of solid and gas, thermal conductivity of tar sands, and heat of reaction are assumed constant and uniform.

(2) The gas and solid temperatures are equal. 
(3) Heat losses and molecular diffusion were not considered. In a more comprehensive model, these effects may be easily incorporated.

Arrhenius type expressions for the oxygen reaction rate $(R)$ and the oil pyrolysis rate $(P)$ were obtained from references [5] and [8] respectively.

Thus:

$$
\begin{aligned}
& R=A_{1} \operatorname{EXP}\left(-E_{1} / T\right) \\
& P=A_{2} \operatorname{EXP}\left(-E_{2} / T\right) .
\end{aligned}
$$

In order to solve the system of equations (3) through (6) (i.e., to obtain the values of $T, N_{1}, N_{2}$, and $W$ as functions of time and space), the values of physical and chemical properties which appear in these equations should be available to the user. A summary of the values used to test the model are found in Table I. In addition, the following expression for the gas flux $\mathrm{m}_{\mathrm{g}}$ was used.

$$
\mathrm{m}_{\mathrm{g}}=\mathrm{m}_{\mathrm{a}}+\mathrm{r}_{0}^{\times} \mathrm{P} \mathrm{dx}
$$

Equation (9) accounts for the change of gas flux as a result of oil production by pyrolysis.

The initial and boundary conditions for this problem are given by: at $t=0$ and all $x$,

$$
\mathrm{T}=294^{\circ} \mathrm{K}, \mathrm{N}_{1}=.23 . \quad \mathrm{N}_{2}=0
$$

at $x=0$ and all $t$,

$$
\mathrm{T}=294^{\circ} \mathrm{K}, \mathrm{N}_{1}=.23 \quad \mathrm{~N}_{2}=0
$$

at $x=L$ and $t<\frac{1}{2}$ hour,

$$
\mathrm{T}=755.5^{\circ} \mathrm{K}
$$

at $x=L$ and $t>\frac{i}{2}$ hour,

$$
\frac{\mathrm{dT}}{\mathrm{dx}}=0
$$


III. Numerical Studies

The rate equations (7) and (8) with the gas flux equation (9) were substituted into the system of partial differential equations (3) through (6). The physical and chemical properties, summarized in Table I, were incorporated with equations (3) through (6) and the resulting system was solved by the method of lines [9]. In this method, the tube is divided into equidistant nodal points. The spatial derivatives in the right hand side of equations (3) through (6) are discretized by a standard finite difference technique, while the temporal partial derivative in the left hand side is replaced by a total derivative. If this procedure is carried out for each nodal point, one obtains a system of ordinary differential equations to be integrated numerically. After each integration step, the gas flux and oil produced are calculated.

Due to the hyperbolic nature of equations (4) and (5), the choice of a finite difference approximation is of utmost importance. In this problem, backward difference approximation is recommended. Other approximations, such as centered difference, will lead to instability.

The choice of ordinary differential equation integration technique is also of utmost importance. For example, the standard Adams or Runge-Kutta integrating methods are unstable in connection with this "stiff" system of ordinary differential equations. This phenomenon has been observed with problems involving fast reaction rates. Instead, the more powerful backward differentiation techniques need to be used[10].

The basic advantage of the method of lines in connection with partial differential equations over finite difference techniques is that at each time step the calculation procedure gives an estimate for the local truncation error. Thus one can change the time step size if the truncation error exceeds a preselected value. In finite difference techniques, such 
a control of time step size is absent and an ad hoc trial and error procedure is necessary in order to select a time step size. Another advantage of the method of lines over finite difference techniques is that the computer program can be easily written and modified, especially when one is dealing with nonlinear equations.

IV. Results and Conclusions

Six computer runs were completed for six different volumetric air fluxes (namely $3.05,6.10,9.14,12.14,15.24,18.29$ standard $\mathrm{m}^{3} / \mathrm{hr}-\mathrm{m}^{2}$, which correspond to $10,20,30,40 ; 50$ and $60 \mathrm{ft} / \mathrm{hr}$ respectively). As air flux increased and temperature and concentration gradients became steeper, instability occurred with improper choice of time and length steps.

After the completion of each run, the following results are obtained at hourly intervals:

(1) Temperature profile

(2) Oxygen concentration profile as a fraction of the original oxygen concentration

(3) Oil concentration profile as a fraction of gas density

(4) The oil accumulated

Figures 1, 2, and 3 illustrate the temperature, oxygen concentration and oil concentration profiles, respectively, at two hour intervals, for an air flux of 9.14 standard $\mathrm{m}^{3} / \mathrm{hr}-\mathrm{m}^{2}$. It can be seen that steady state conditions were achieved within six hours. The other computer runs indicate that as the air flux is reduced below $9.14 \mathrm{~m}^{3} / \mathrm{hr}-\mathrm{m}^{2}$, steady state conditions are not attained. It can be deduced from this that the steady state analysis presented in the introduction is only valid for air fluxes in excess of 9.14 standard $\mathrm{m}^{3} / \mathrm{hr}-\mathrm{m}^{2}$, and that the slabllization time in such cases is on the order of two hours. 
In Figures 4 and 5, the effect of air flux on the peak temperature and flame velocity are presented respectively. In Figure 6, oil recovery efficiency is plotted versus.air flux. Here the recovery efficiency is defined as the fraction of original oil in place which was produced by the reverse combustion techniques. It is to be noted from Figure 6 that for air fluxes in excess. of 12 standard $\mathrm{m}^{3} / \mathrm{m}^{2} \mathrm{hr}$, no appreciable increase of oil recovery efficiency is observed. This may be explained as follows: As air flux increases, the peak temperature increases, and this increases both the oxygen reaction rate and oil pyrolysis rate. Thus, as temperature increases, more oil is pyrolysized, but also more oil reacts. with oxygen. Experimental results by Land [5] indicate that oil recovery decreases slightly for air flux of 18 s.tandard $m^{3} / m^{2} h r$.

The results shown in figures 4 and 6 were compared with the experimental results of Land [6] and were found to be in satisfactory agreement as shown in Table II. The discrepancy between the experimental and numerical values may be attributed to the uncertainty in the physical and chemical properties outlined in Table $I$. The fact that the temperatures attained in the numerical runs are consistently higher than the corresponding experimental values indicates that the adiabatic conditions assumed here are too stringent.

Finally, the results here are important for the study of the effects of various parameters on the recovery efficiency and illustrate the viability of the method of lines for such a study. However, the technique presented here becomes more important if two- or three-dimensional flows are considered. In such circumstances, steady state analysis becomes very difficult; and short of an expensive field experiment, the only methods available to us are numerical techniques such as presented here. 


\section{Acknowledgments}

This work was supported by ERDA contract E(29-2)-3694 and DOE. contract EY-77-C-04-3913 with. the Rocky Mountain Institute of Energy and Environment (RMIEE). The author wishes to thank the tar sand project staff at Laramie Energy Technology Center who provided help at every stage of the project. In particular, thanks are due to L. C. Marchant, L. Dockter, and R. V. Barbour of LETC. 
Table I

Physical and Chemical Data

$$
\begin{array}{rlrl}
c_{g} & =1.03 & & \mathrm{~kJ} / \mathrm{kg} \mathrm{K} \\
c_{s^{\rho}} & =2346.88 & \mathrm{~kJ} / \mathrm{m}^{3} \mathrm{~K} \\
\phi & =0.26 & & \text { Dimensioniess } \\
\mathrm{K} & =5.3 & \mathrm{~kJ} / \mathrm{hr}-\mathrm{m} \mathrm{K} \\
\rho_{\mathrm{g}} & =1.027 & \mathrm{~kg} / \mathrm{m}^{3} & \mathrm{~kg} \text { of oxygen } / \mathrm{m}^{3} \mathrm{hr} \\
\mathrm{A}_{1} & =31.395 \times 10^{6} & \mathrm{~K} \\
\mathrm{E}_{1} & =6944.44 & \mathrm{~kJ} / \mathrm{kg} \text { of oxygen } \\
\mathrm{H} & =12,908.4 & \mathrm{hr} & \\
\mathrm{A}_{2} & =5.94 \times 10^{10} & \mathrm{~K} . \\
\mathrm{E}_{2}=16,666.67 & \mathrm{~kg} \text { of oil } / \mathrm{m}^{3} \\
\mathrm{M}_{\mathrm{O}} & =160.18 &
\end{array}
$$




\section{Table II}

\section{Comparison Between Numerical Results}

and Experimental Results of Reference [5]

\section{Air FIux}

$\mathrm{cm} / \mathrm{m}^{2} \mathrm{hr}$

6.10

9.14

12.19

15.24

18.29
Maximum Temperature (K)

Experimental

$610 \cdot 00$

658.90

$713: 89$

728.89

756.10
Numerica1

637.90

683.17

722.61

756.03

785.48

Recovery Efficiency (\%)

Experimental

29.0

40.8

43.5

49.6

40.5
41.5

14.4

30

40

44 
BIBLIOGRAPHY

1. Cupps, C.Q., Land, C.S., and Marchant, L.C., "Field Experiment of In Situ Oil Recovery from Utah. Tar Sand by Reverse Combustion," AICHE Symposion Series 155, Vol. 72, 1976, pp 61-68.

2. Berry, V. J. and Parrish., D. R., "A Theoretical Analysis of Heat Flow in Reverse Combustion," Trans. AIME, Vol. 219, 1960, p. 124.

3. Warren, J. E., Reed, R. L., and Price, H. S., "Theoretical Considerations of Reverse Combustion in Tar Sands," Trans. AIME, Vol. 219, 1960 , p. 104.

4. Kotowski, M. D. and Gunn, R. D., "Theoretical Aspects of Reverse Combustion in the Under Ground Gasification of Coal," Department of Energy/LERC/RI - 76/4.

5. Land, C. S., "Reverse Combustion in Tar Sands," Ph.D. Dissertation, University of Wyoming, Laramie, Wyoming, 1974.

6. Land, C. S., Carlson, F. M., and Cupps, C. Q., "Laboratory Investigation of Reverse Combustion in Two Utah Tar Sands," ERDA/LERC/RI $75 / 2$.

7. Reed, R. L., Reed, D. W., and Tracht, J. H., "Experimental Aspects of Reverse Combustion in. Tar Sands," Transaction AIME, 219, p.99, 1960 .

8. Barbour, R. V., Dorrence, S. M., Vollmer, T. L., and Harris, J. D., "Pyrolysis of Utah Tar Sands - Products and Kinetics," Div. of Fuel Chemistry, Am. Ch. Soc., 21(6), pp 278-283 (1976).

9. Sinovec, A., "Numerical Reservoir Simulation Using an Ordinary Differential Equations Integrator," Society of Petroleum Engineers Journa1, pp 225, June 1975.

10. Hindmarsh, A. C., "GEARB: Solution of Ordinary Differential Equations Having Banded Jacobian," Rep. UCID - 30069, Lawrence Livermore Lab., Livermore, Calif., May 1973. 
CAPTIONS. FOR FIGURES THAT FOLLOW

Figure 1: Temperature profiles at two-hour intervals along the tube length

Figure 2: Oxygen concentration profile as a fraction of original oxygen mass fraction at two-hour intervals along the tube length

Figure 3: Oil concentration as a fraction of mass flux at two-hour intervals along the tube length

Figure 4: Peak temperature versus volumetric air flux

Figure 5: Flame velocity versus volumetric air flux

Figure 6: 0il recovery efficiency versus volumetric air flux 
Figure 1.

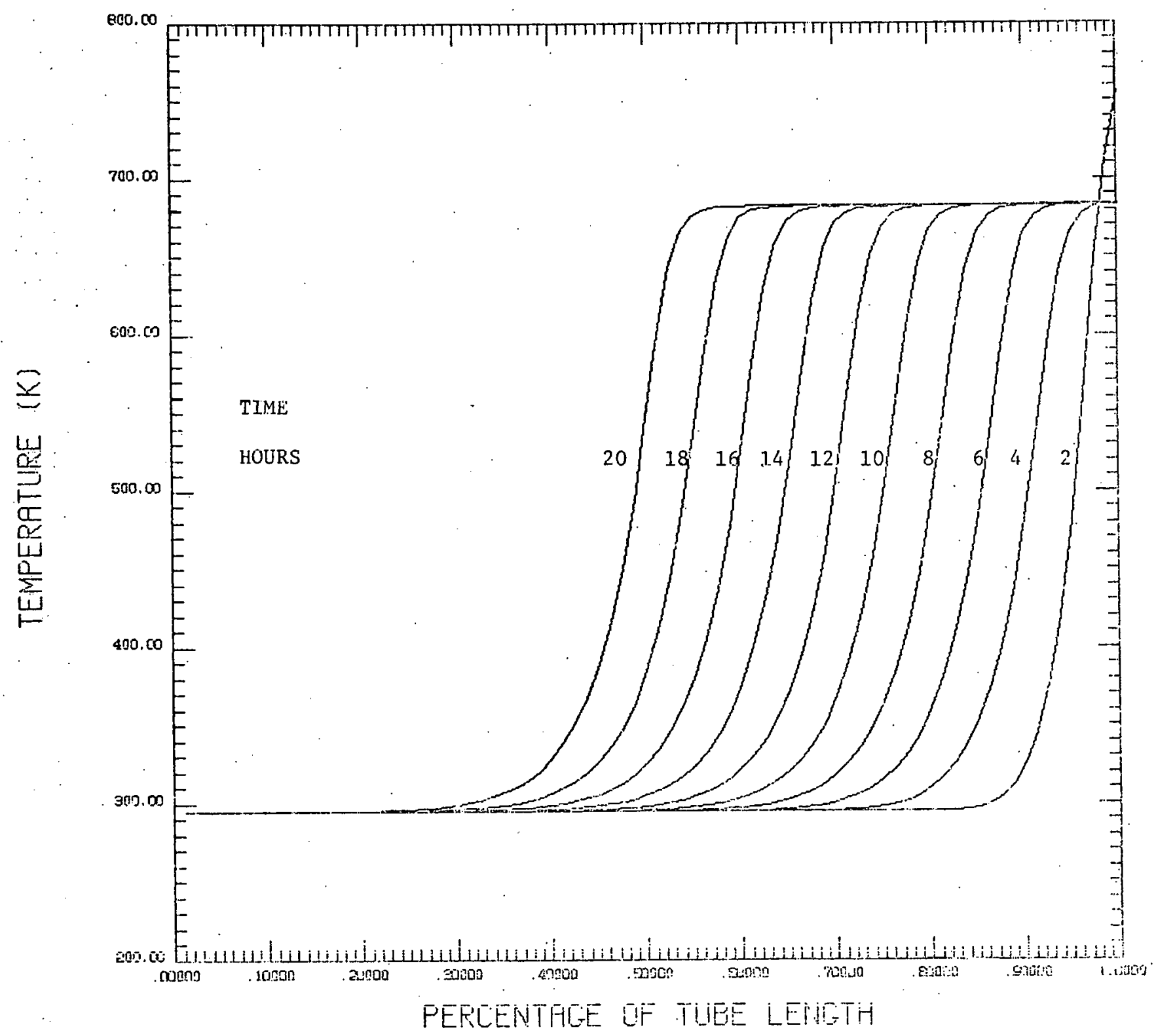


Figure 2

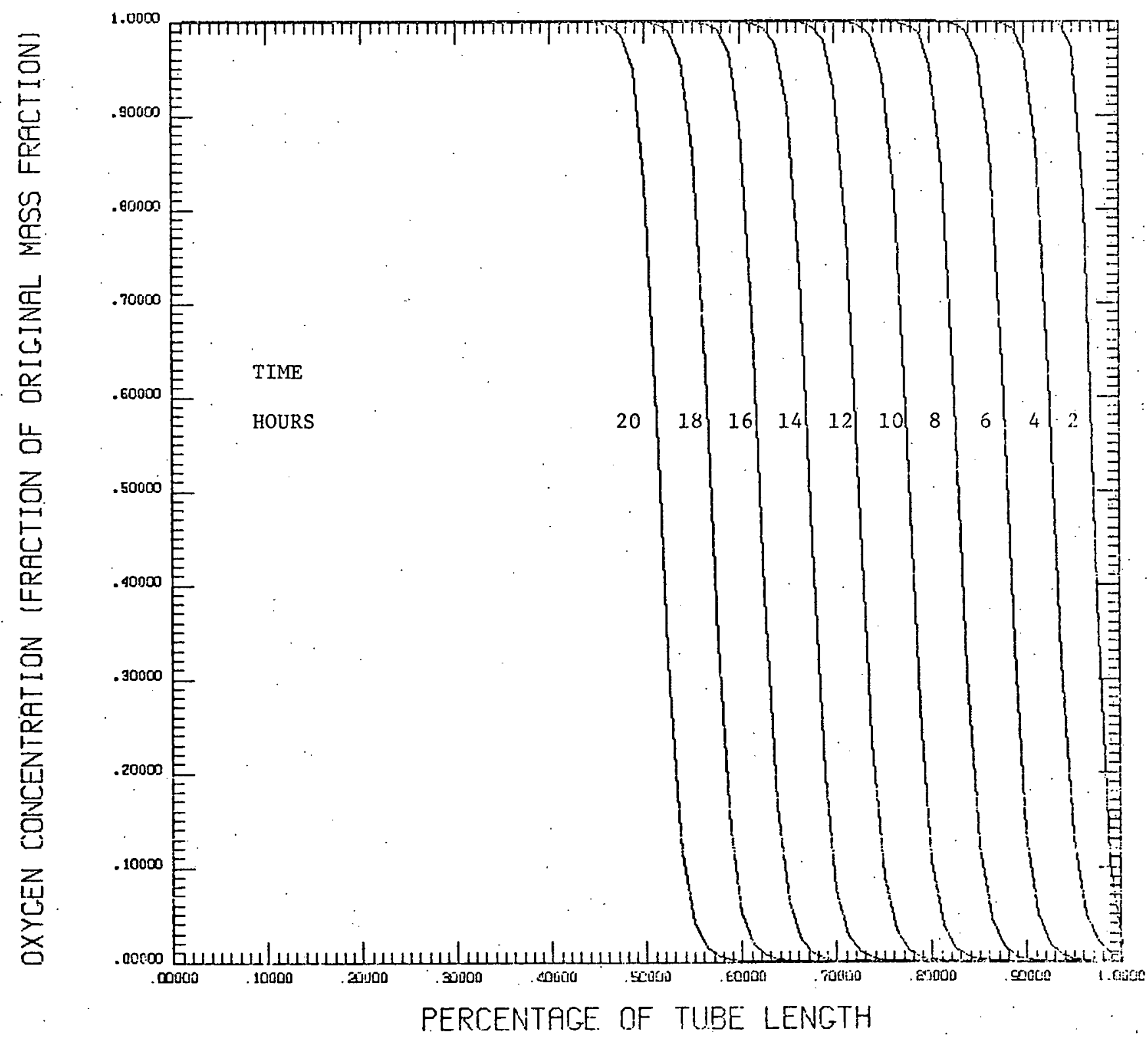


Figure 3

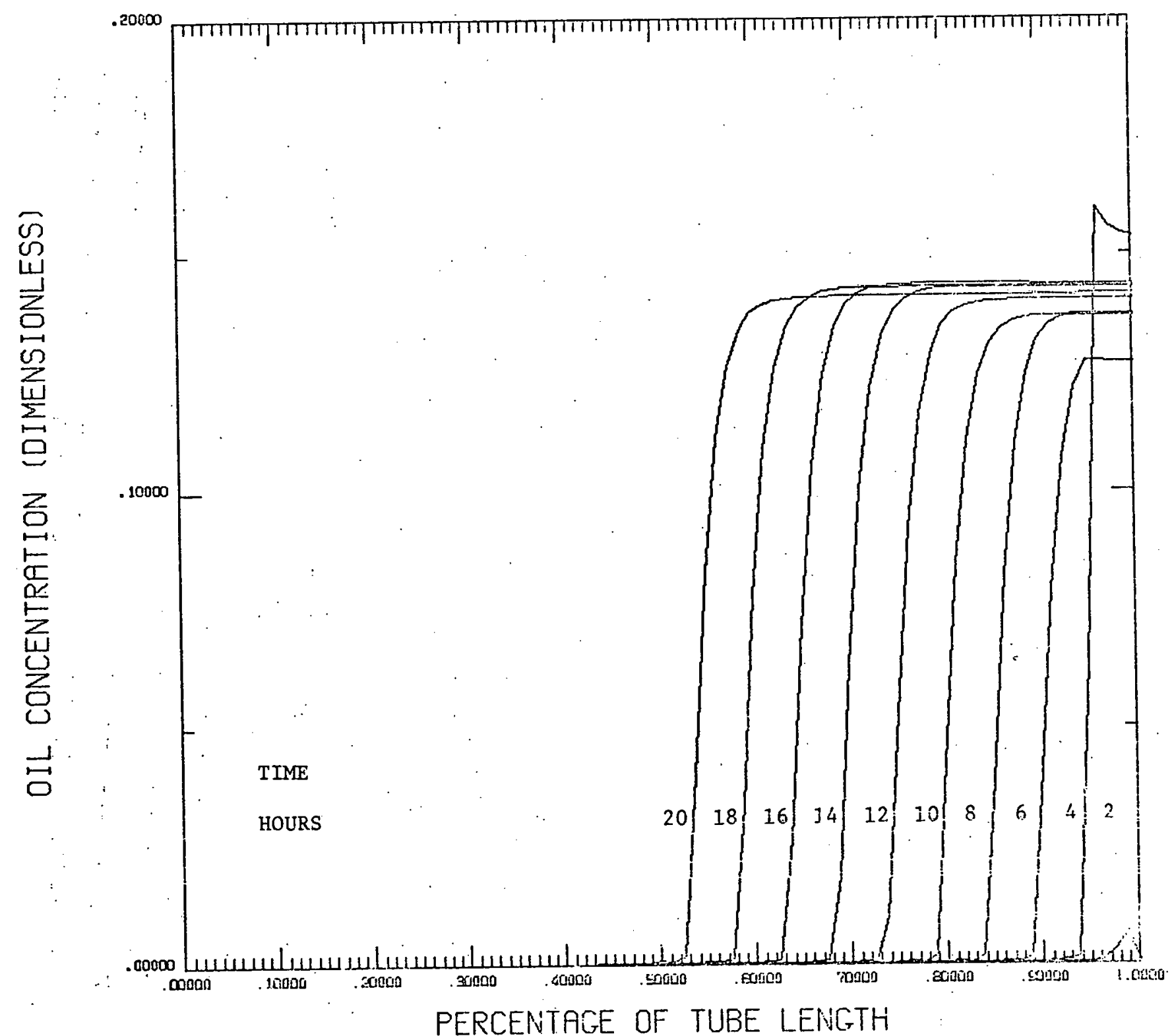


Figure 4

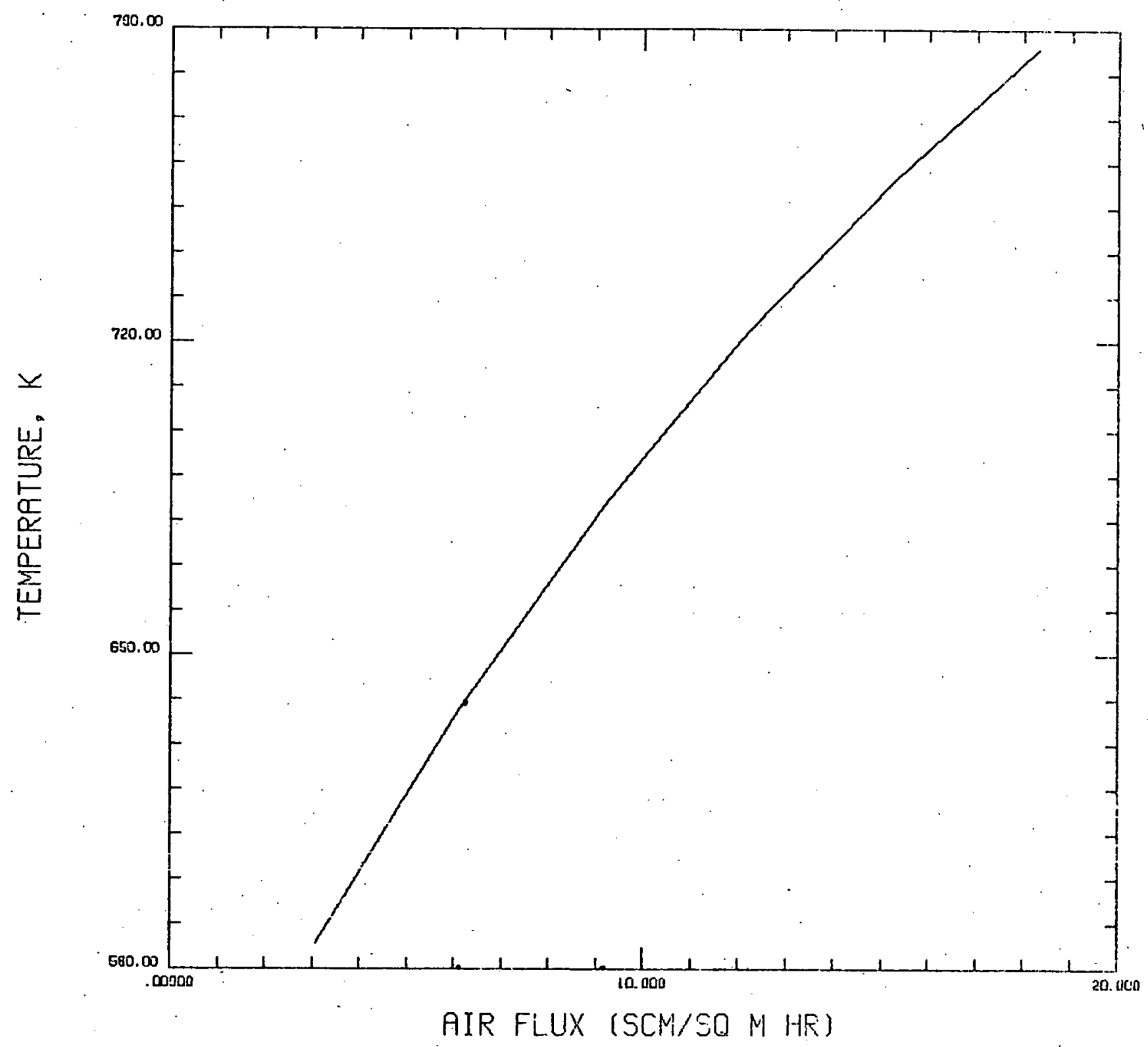


Figure 5

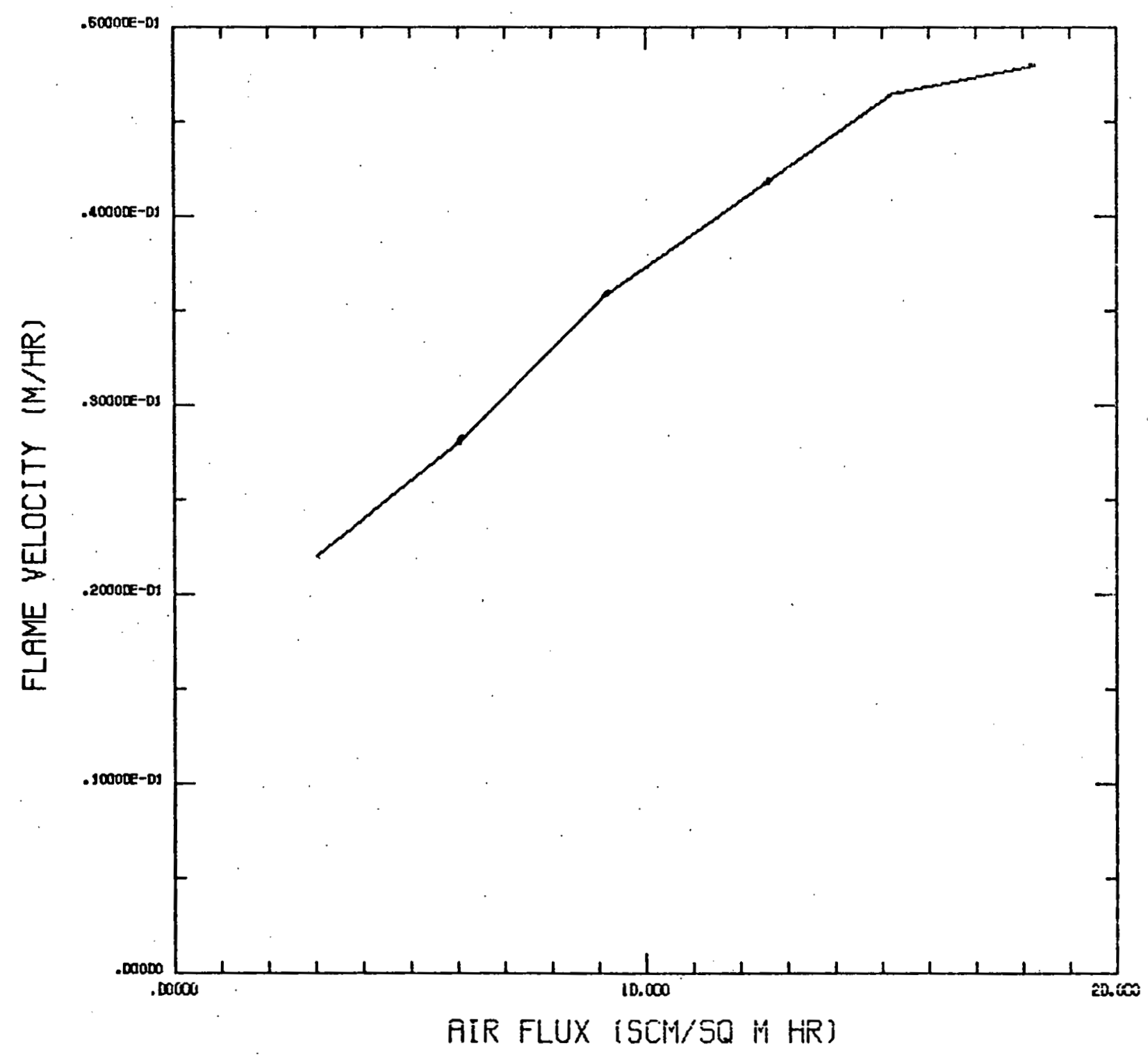


Figure 6

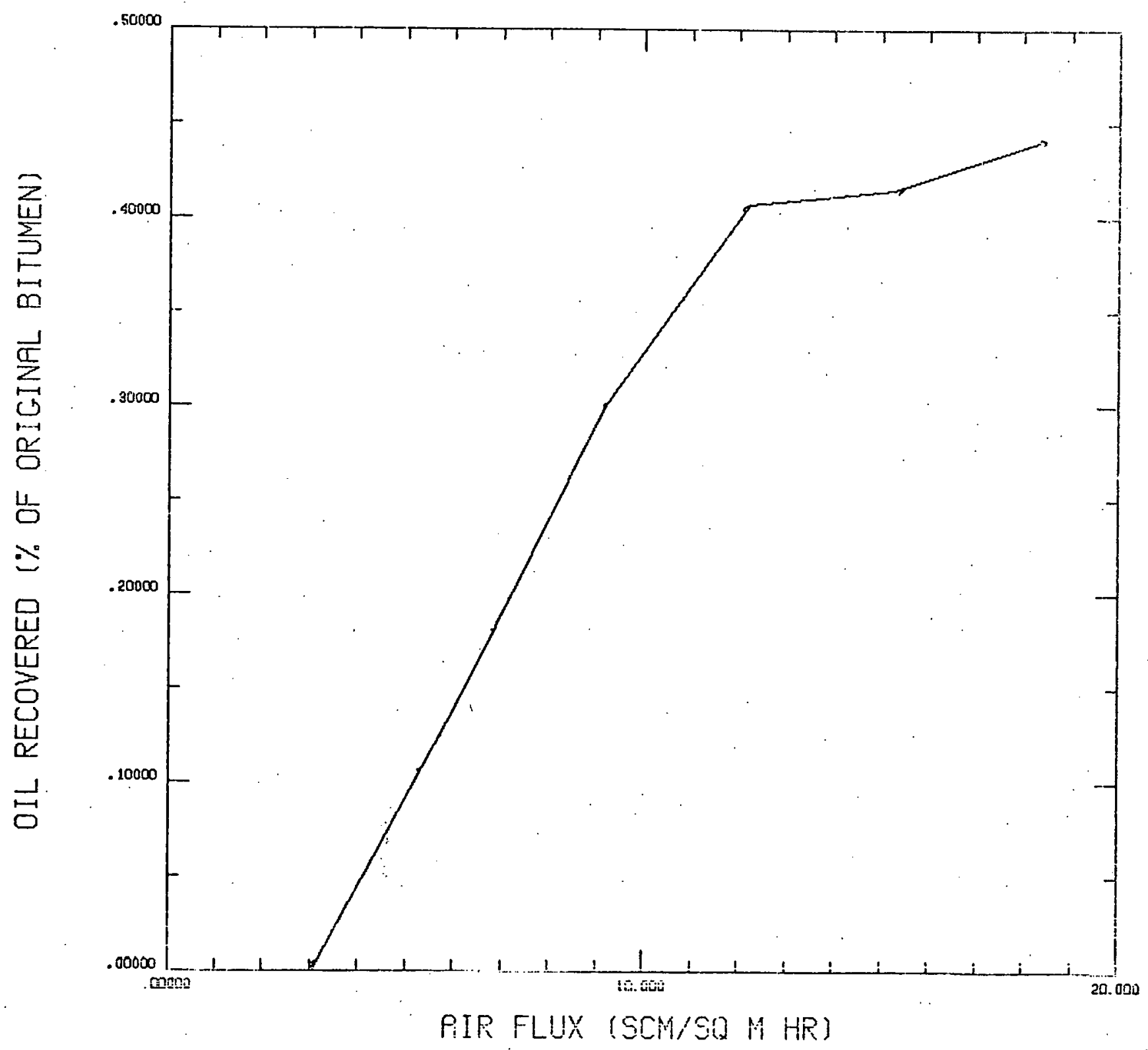


APPENDIX A

One Dimensional Reverse Combustion Program "COMBU" 
Description of the Computer Program "COMBU"

The computer program "COMBU" developed under this contract solves equations (3) through (6), subject to the boundary and initial conditions outlined above. The version of COMBU described in this appendix and which is listed in Appendix B, is based on the English System of units. Minor modifications of the program are needed to convert to the international system of units.

An automatic ordinary differential equation integrator developed at the Lawrence Livermore Laboratory under the code name GEARB must be used together with. COMBU. For a detailed description of GEARB the reader is referred to an article by Hindmarsh [10].

The computer program COMBU consists of four segments; the main program, subroutine DIFFUN, subroutine PDTP, and subroutine DRIVEB.

In the main program, the coefficients needed in equations (3) through (6) are calculated and the initial conditions are formulated. Subsequently, the main program functions as a driver for the integration processes. Final1y, program output is handled in this segment. The subroutine DIFFUN provides the system of ordinary differential equations, together with the boundary conditions required by the method of lines. The subroutine PDP calculates the Jacobian for these ordinary differential equations. The Jacobian is required in the backward differention techniques. Finally, the subroutine DRIVEB is the automatic differential equations integrator referred to above by GEARB.

\section{A-Input Data}

Physical and chemical data pertaining to the problem should be provided by the user. In all, nineteen constants are needed, eleven of which 
were described in Table $I$. All input data require nineteen input cards read by. FORMAT (F 19.6). The contents of these cards are described below. It is to be noted that the English System of units has been included in this version.

Card 1 - Contain CG = specific heat of produced gas in Btu/1b ${ }^{\circ} \mathrm{F}(\mathrm{e} . \mathrm{g} .=245)$. Card 2 - Contains PHIG = poros1ty, non-dimensional. $(\mathrm{e} . \mathrm{g} .=.26)$. Card. 3 - Contains GAMAMC = heat capacity per unit matrix volume in $\mathrm{Btu} / \mathrm{ft}^{3 \circ} \mathrm{F}(\mathrm{e} . \mathrm{g} \cdot=35)$

Card 4 - Contains $A H=$ heating value of oil in But/1b (e.g. = 5550). Card 5 - Contains $\mathrm{CO}=$ original oxygen mass fraction in air, nondimensional (e.g. $=.23)$.

Card 6 - Contains GAMAG = average produced gas density in $1 \mathrm{~b} / \mathrm{ft}^{3}$ or from ideal gas formula: density $=\operatorname{GAMAG} /\left(\operatorname{temp}^{\circ} \mathrm{R}\right)(\mathrm{e} . \mathrm{g}:=115.3)$.

Card 7 - Contains $\mathrm{AK}=$ thermal conductivity of solid matrix in Btu/ $\mathrm{hrFt}^{\circ} \mathrm{F}(\mathrm{e} \cdot \mathrm{g} \cdot=.85)$.

Card 8 - Contains $\mathrm{U}=$ standard air flux in SCF $/ \mathrm{ft}^{2} \mathrm{hr}$ at 1 atm and $60^{\circ} \mathrm{F}$ (treated as a parameter).

Card 9 - Contains $E$ = activation energy for oxygen-oil reaction ${ }^{\circ} \mathrm{R}$ $(\mathrm{e} \cdot \mathrm{g} \cdot=12,500)$.

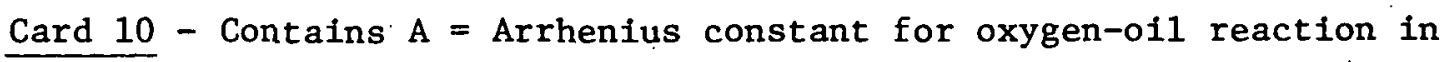
$1 \mathrm{~b}$ of oxygen/ft $\mathrm{ft}^{3} \mathrm{hr}\left(\mathrm{e} \cdot \mathrm{g} .=1.96 \times 10^{6}\right)$.

Card 11 - Contains $E 2$ = activation energy for oil pyrolysis in ${ }^{\circ} R$ $(\mathrm{e} \cdot \mathrm{g} \cdot=30,000)$.

Card 12 - Contains A2 = Arrhenium constant for oil pyrolysis in $\mathrm{hr}^{-1}$ $\left(\mathrm{e} . \mathrm{g} .=5.94 \times 10^{10}\right)$. 
Card 13 - Contains GAMAG2 = air density under standard conditions in $1 \mathrm{~b} / \mathrm{ft}^{3}(\mathrm{e} \cdot \mathrm{g} \cdot=.076)$.

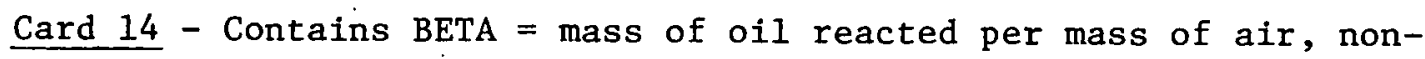
dimensional (e.g. $=0.541)$.

Card 15 - Contains OILM = Ibs of oil available for combustion and/or production per cubic foot of solid matrix (a variable which depends on temperature, and considered constant for each run) $(\mathrm{e} . \mathrm{g} \cdot=10)$.

Card 16 - Contains FEET = length of combustion tube in feet (e.g. = 4). Card 17 - Contains TMAX = time at which integration stops, in hours $($ e.g. $=30)$.

Card 18 - Contains DTHET = time step, in hours, a value less than $2.5 \times 10^{-3}$ is recommended.

Card 19 - Contains $W 11=$ time of heating the tube end at exit, in hours (e.g. $=.5$ for $U \leq 30$ and $=1$ for $U<30$ ).

\section{B-Program Output}

The reader is referred to Appendix $C$ for a sample printout.

1. The program lists all nineteen input values by the designation described above. In addition, the length increment $\mathrm{DX}$ and the number of equation to integrated NFUNCT are 1isted.

2. The results at each time step are preceded by numbers. The first number is the last time step used. The second number is an index for the integration procedure (usually equal to two except for the first step where it is equal to one); the third number is NFUNCT, the number of oquation lu be inceggrated. Finally, the last number is the current time in hours, for which the results are listed. 
3. Under the heading, "TEMPERATURE," the values of the temperature at the current time are 1isted for each mesh point starting from the inlet end.

4. Under the heading, "OXYGEN CONCENTRATION," the values of oxygen concentration as a percentage of the original oxygen concentration at inlet, are listed for each mesh point. A value of one under this heading indicates no reaction with oxygen did occur.

5. Under the heading, "OIL CONCENTRATION," the values of ofl vapor concentration in the gas stream ( $1 \mathrm{~b}$ of oil per $1 \mathrm{~b}$ of gas mixture) are 1isted for each point.

6. Under the heading, "JWW," the values of the fraction of oil in place, which is pyrolyzed, are listed. A value of one means that only coke is left in place.

7. The mass flow rate per unit area at exit, "LAST DOTM", and the mass of oil collected up to this time,"SUMOIL"' are listed.

8. The results are printed at hourly intervals in the format described in item 2 through 7.

\section{C-Notes on the Use of the Program}

1. The program uses eighty mesh points; if fewer points are desired, the user has to change card number 26 in the main program so that JJBED $=$ number of mesh points. If more than eighty points are required, in addition to the above change, the user has to change three "DIMENSION" statements; one in the main program, and one each in subroutine DIFFUN and PDP, such that the statements read:

$$
\text { DIMENSION DOTM(JJBED), P (4*JJBED), DERYL ( } 4 * \text { JJBED) }
$$

where: 
JJBED is the new number of mesh points.

2. It is to be noted that a portion of the Bitumen in the tar sands converts to coke which is not available for combustion. The amount of coke formed is a strong function of temperature. The value of OILM described in the input data, card 15, is the difference between the oil in place and the coke formed. Thus OILM is also a function of temperature. and thus is not known at the beginning of the computer run. To avoid this difficulty, the following procedure is suggested: A preliminary run is conducted with OILM taken as the oil in place up to time equal to five hours. This run will determine the temperature profile which is insensitive to the value of OILM. Once the maximum temperature is known for a given air flux, a more realistic OILM can be estimated. Namely, experimental data are available which relate OILM as a function of temperature [7].

3. A complete run requires between 20 to 50 minutes of computer time using the University SIGMA 7 .computer. 
APPENDIX B

Listing of Program COMBU 


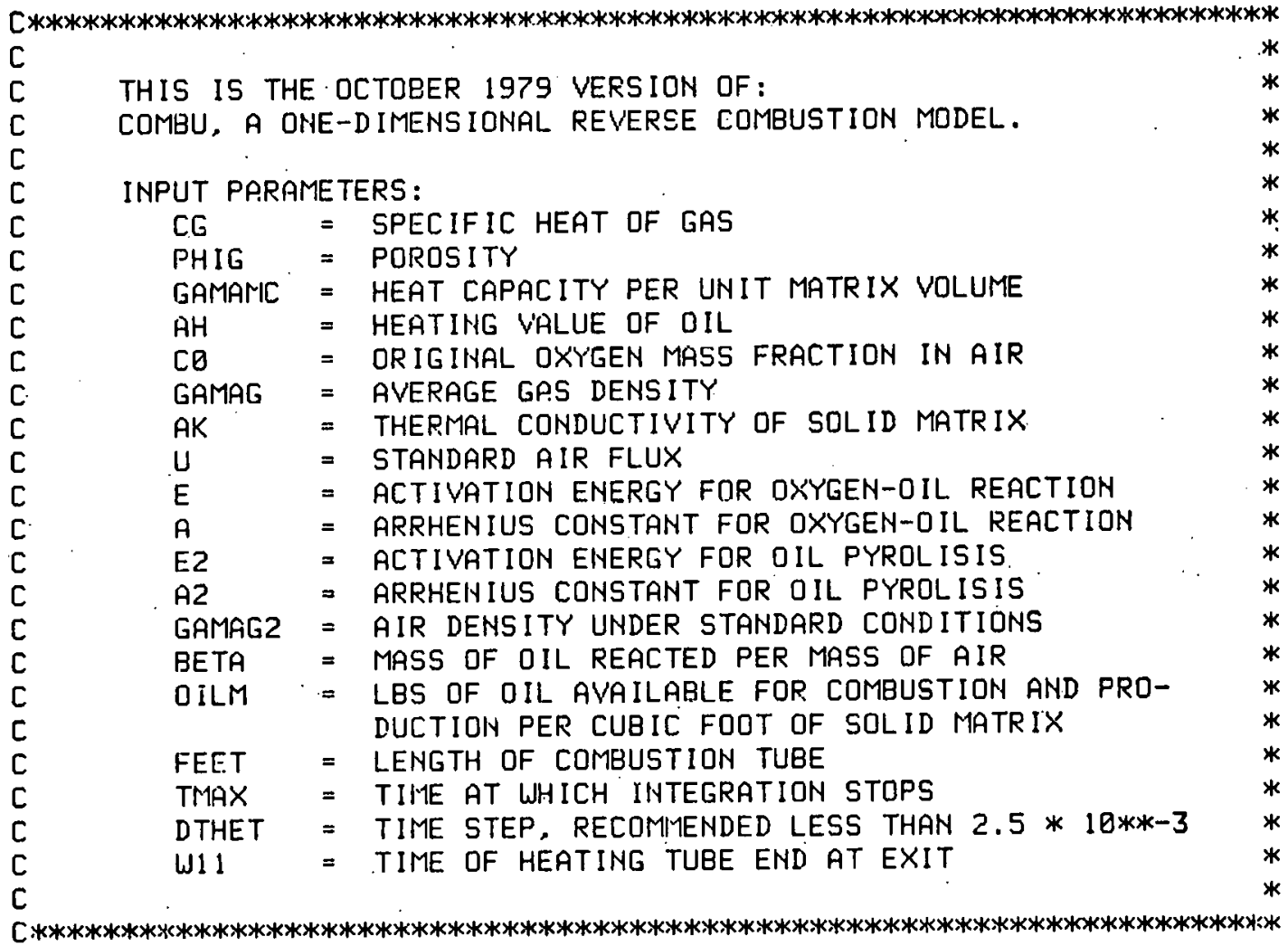

DIMENSION DOTM(80), $P(320)$

COMM1ON WQ, W1, W2, W3, W4, W5, W6; W7, W8, W11, A2, OILM, DOTM, DTHET, DX, E, E2, JJBED

READ $(5,100)$ CG, PHIG, GalMamC, AH, CO, GAMAG, AK, U, E, A, E2,

A2, GAMAG2, BETA, OILM, FEET, TMAX, DTHET, WII

$\mathrm{JJBED}=80$

$\mathrm{N}=4 * \mathrm{JJBED}$

$\mathrm{DX} \quad=$ FEET $/(\mathrm{JJBED}-1 . \mathrm{B})$

WRITE $(3,110)$ CG, PHIG, gamamC, AH, CO, GAMAG, AK, U, E, A, EZ,

A2, GATIAG2, BETA

C*****:k***********************************

$\begin{array}{ll}\text { C } & \\ \text { C VARIABLE INITIALIZATION. } & * \\ \text { C } & *\end{array}$

C****************************************

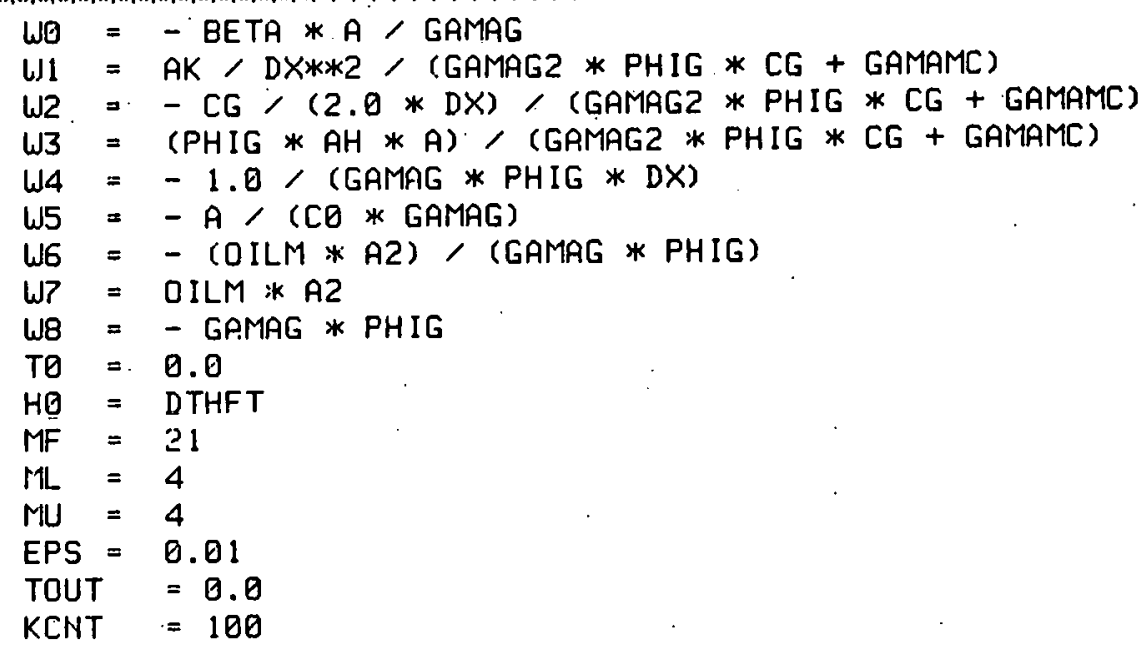




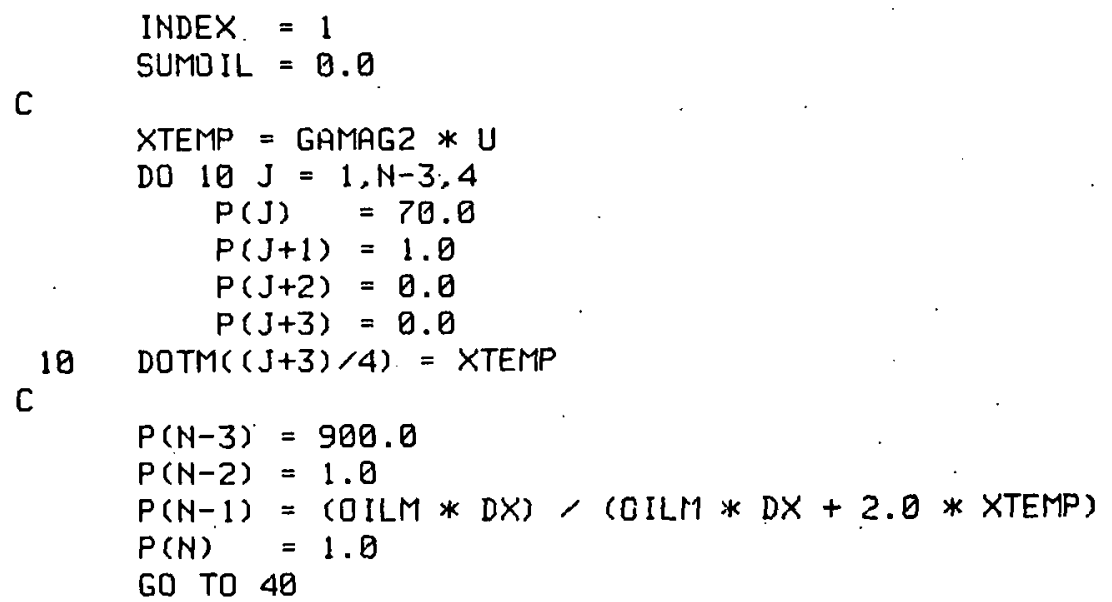

[ж**********:***********************************************

$\begin{array}{lll}\text { C } & \text { CALL DRIVEB TO INTEGRATE THE SYSTEM } & * \\ \text { C } & * \\ \text { C } & \text { OF FOUR O.D.E.'S AT TIME }=\text { TOUT. } & * \\ \text { C } & & *\end{array}$

20 CALL DRIVEB (N, TO, HO, P, TOUT, EPS, MF, INDEX, ML, MU)

INDEX $=2$

$\operatorname{DOTM}(2)=\operatorname{DOTM}(1)+(1 . \theta-P(4)) * W 7 * D X *$

- $\quad \operatorname{DEXP}(-E 2 /(P(1)+460.0))<2.0$

DO $30 \mathrm{~J}=3$, JJBED

$W W=1.0-P(J * 4-4)$

$R P=W 7 *$ WW $* \operatorname{DEXP}(-E 2 /(P(J * 4-7)+460.0))$

$P 2=$ WW $*$ OILM $/$ DTHET

IF (RP .GT. P2) RP $=P 2$

$30 \operatorname{DOTIM}(\mathrm{J})=R P * D X+\operatorname{DOTM}(\mathrm{J}-1)$

SUMOIL $=$ SUMOIL + DOTM(JJBED) $* P(N-1) *$ DTHET

C*********************************************************

C

C OUTPUT EVERY 100TH SOLUTION. * *

$[* * ; k * * * * * * * * * * * * * * * * * * * * * * * * * * * * * * * * * * * * * * * * * * * * *$

40 IF (KCHT .LT. 100) GO TO 50

$\mathrm{KCNT}=0$

WR ITE (3,120) HO, INDEX, $N$, TOUT

WR ITE (3, 130)

WR I TE $(3,14 \theta)(P(J), J=1, N-3,4)$

WR I TE $(3,150)$

WR I TE $(3,140) \quad(P(J), J=2, N-2,4)$

WR ITE $(3,160)$

WRITE $(3,140) \quad(P(J), J=3, N-1,4)$

WR ITE $(3,170)$

WRITE (3,148) $\quad(P(J), J=4, N, 4)$

WRITE $(3,180)$ DOTM(JJBED), SUMOIL

$50 \quad K C N T=K C N T+1$

TOUT = TOUT + DTHET

IF (TOUT .LE. TMAX) GO TO 20

C************************************************

C

C PROGRAM EXIT.

C************************:k*********;

WR ITE $(3,190)$ HO, INDEX, N, TOUT, SUMOIL

STOP 
C

100 FORMRT (18(F 19.6, /),F 19.6)

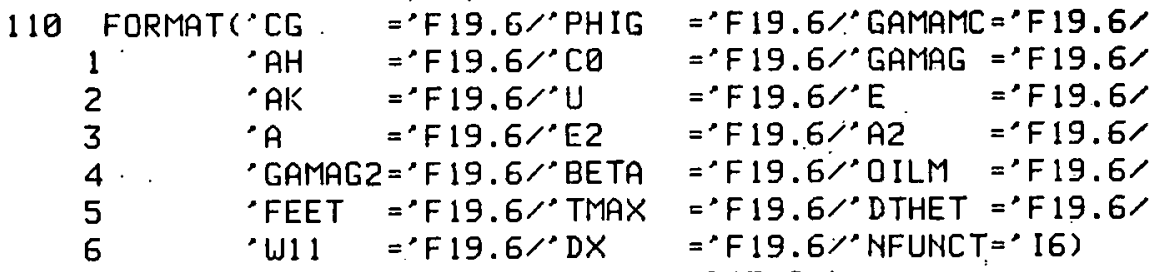

120 FORMAT $(/ / / / / * * * * * * * * *$ F 13.9, 2 I6, F 13.9/)

130 FORMAT ( $1 \times$.' TEMPERATURE')

140 FORMAT (1X, 10F 12.6)

150 FORMAT ( $1 \times$, "OXYGEN CONCENTRATION")

160 FORMAT ( $1 X$, ,OIL CONCENTRATION')

170 FORMAT (1X, "Jالسالس")

180 FORMAT(" LAST DOTM - - 'F13.9/" SUMOIL --..'F13.9)

190 FORMAT(ノノ"*DONE*'F13.9.2I6.F13.9\%" SUMOIL --- "F13.9)

END

C**************************************************************************************

C

DIFFUN COMPUTES: DERYI F(P T) THE RIGHT SIDE OF THE

$\begin{array}{llll}\text { C DIFFUN COMPITES: } & \text { DERY } 1=F(P, T), \text { THE RIGHT SIDE OF THE } & * \\ \text { C } & \text { O.D.E. INPUT TO DRIVEB FOR SOLUTION. } & *\end{array}$

C $P$ AND DERY1 ARE VECTORS OF LENGTH $N$. *

$\begin{array}{lll}\text { C THIS ROUTINE IS CALLED BY DRIVEB. } & * \\ \text { C } & & *\end{array}$

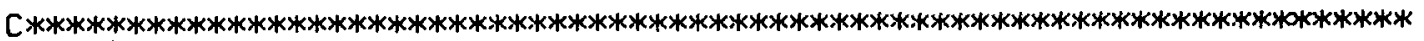
SUBROUTINE DIFFUN (N,T,P,DERY 1)

DIMENSION DOTM(80), P(326), DERYI (320)

COMMON WQ, W1, W2, W3, W4, W5, W6, WP, W8, W11, A2, OILM,

DOTM, DTHET, DX, E, E2, JJBED

C*********************************************************************

C

C DERIVATIVES AT LOLER BOUNDARY.
C
C**********************************************************

c

$$
\begin{array}{lll}
\text { IF }(P(2) & \text {.LT. } 0.0) & P(2)=0.0 \\
\text { IF }(P(3) & . \text { LT. } 0.0) & P(3)=0.0 \\
\text { IF }(P(4) & \text {.GT. } 1.0) & P(4)=1.0
\end{array}
$$

$T T=P(1)+460.0$

$X X=P(2) * \operatorname{DEXP}(-E / T T)$

$R P=W P *(1 . \theta-P(4)) * \operatorname{DEXP}(-E 2 / T T)$

C

$Y Y=R P / W 8$

DERY $1(1)=2.0 * W 1 *(P(5)-P(1))+W 3 * X \times$

DERYL $(2)=0.0$

DERY 1 (3) $=($ W $* X X+P(3) * Y Y-Y Y) * T T$

DERY I (4) $=$ RP $/$ OILM

C************************************************************

C

C NON-BOUNDARY DERIVATIVES.

C

[ж******************************************************

DO. $500 \mathrm{JT}=5, \mathrm{~N}-7,4$

$$
\begin{aligned}
& J C=J T+1 \\
& J F=J T+2 \\
& J W=J T+3 \\
& I=(J T+3) ; 4
\end{aligned}
$$

C

IF $(P(J C) . L T . \theta . \theta) \quad P(J C)=0.0$ 
IF ( $P(J F)$.LT. 0.0.) $\quad P(J F)=0.0$

IF ( $P(J W) . G T .1 .0) \quad P(J W)=1.0$

C

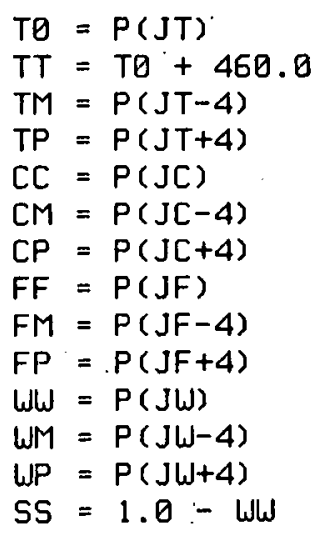

$\cdot \mathbf{C}$

$\operatorname{DOTM}(I)=\operatorname{DOTM}(I-1)+R P * D X$

IF (I .EQ. 2) $\operatorname{DOTM}(2)=\operatorname{DOTM}(1)+R P * D X<2.0$

$D T=\operatorname{DOTM}(I)$

$X X=C C * \operatorname{DEXP}(-E, T T)$

C

$\mathrm{RP}=\mathrm{WP} * \mathrm{SS} * \mathrm{DEXP}(-\mathrm{E} 2<\mathrm{TT})$

IF (T .LT: 3.0) GO TO 400

IF (WM.GE. 1.0 .AND. WP .GE. 1.0) GO TO 300

IF (TO.LT. 200.0) GO TO 200

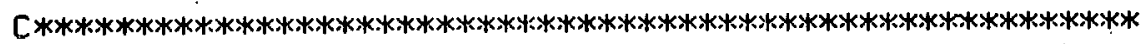

C

$\mathrm{C}$

FIND RVERAGE WEIGHTED VALUES FOR RP AND XX. $\quad *$

C

C****************************************************************

$X=((3.0 * T \theta+T M) \cdot 4.0)+460.0$

$. Y=(3.0 * W W+W M) / 4.0$

$Z=(3.0 * C C+C M) / 4.0$

$R P 1=(1 . \theta-Y) * \operatorname{DEXP}(-E 2, X)$

C

$X X 1=Z * \operatorname{DEXP}(-E, X)$

C

$X=((3.0 * T \theta+T P) / 4.0)+460.0$

$Y=(3.0 *$ Wll + WP $) / 4.0$

$Z=(3.0 * C C+C P)>4.0$

$\mathrm{RP2}=(1 . \theta-Y) * \operatorname{DEXP}(-E 2 / X)$

$X X 2=Z * \operatorname{DEXP}(-E, X)$

$$
\begin{aligned}
& R P=W P *(R P 1+R P 2) / 2.0 \\
& X X=(X X 1+X X 2) / 2.0 \\
& G O \text { TO } 400 .
\end{aligned}
$$

[*****************************************

$\begin{array}{ll}\text { C NO AVERAGING. } & * \\ \mathrm{C} & * \\ \mathrm{C} & *\end{array}$

C:******************************:k***;k*****

$200 \quad X X=0.0$

$300 \quad$ RP $=0.0$

400 $\quad$ P2 $=$ OILM $*$ SS, DTHET

IF (RP . GT. P2) RP. $=P 2$

C

$$
Y Y=R P / W B
$$

$$
\begin{aligned}
\text { DERYI }(J T)= & W 1 *(T P+T M-T O * 2.0) \\
& +W 2 *(T P-T M) * D T+W 3 * X X
\end{aligned}
$$




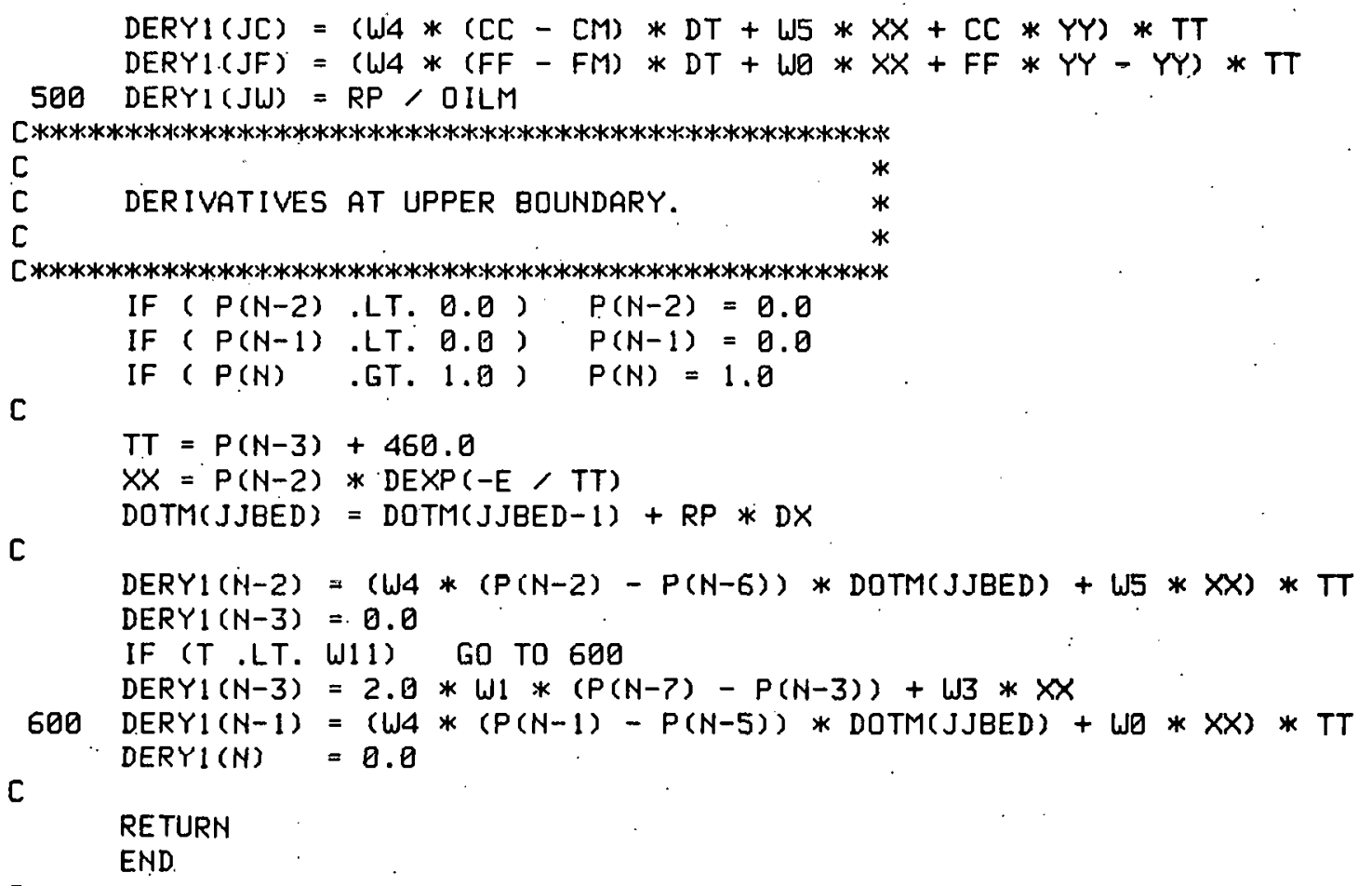

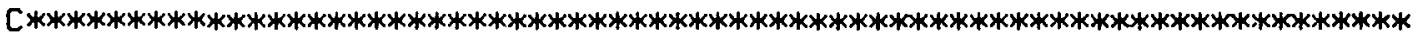

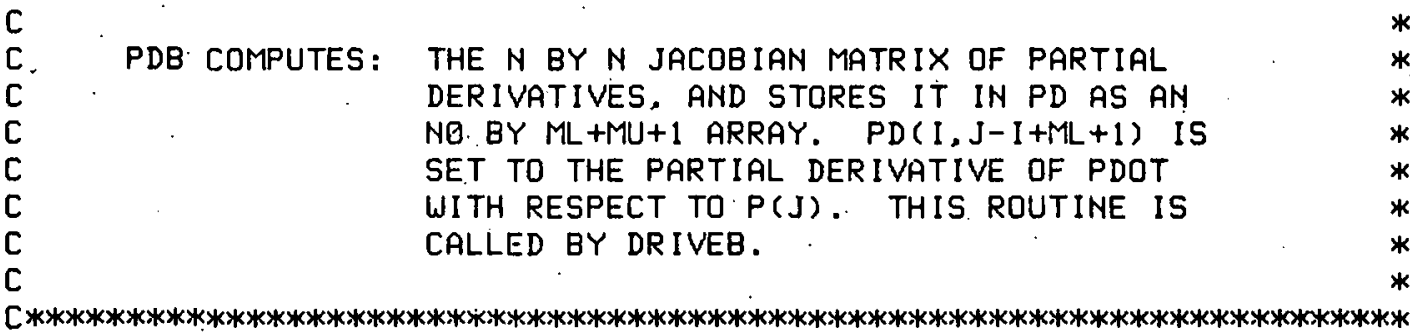
SUBROUTINE PDB (N, T,P,PD, NO, ML, MU)

DIMENSION DOTM(B日), $P(320), P D(320,9)$

COMPION WO, W1, W2, W3, W4, W5, WG, W?, WB, W11, A2, OILM. DOTM, DTHET, DX, E, E2, JJBED

C*******************************:*******************************

$\mathrm{C}$

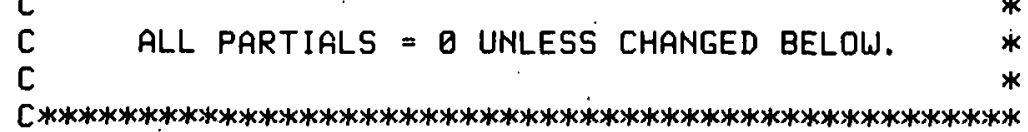

DO $100 \mathrm{~J}=1, \mathrm{~N}$

100 DO $100 . I=1.9$

C****************************************4:*******

$\begin{array}{lll}\text { C } & & \\ \text { C } & \text { PARTIALS AT LOLER BOUNDARY. } & * \\ \text { C } & *\end{array}$

C****************************************************

$$
\begin{aligned}
& T T=P(1)+460.0 \\
& C C=P(2) \\
& F F=1.0-P(3) \\
& W W=1.0-P(4) \\
& Y=D E X P(-E / T T) \\
& Z=D E X P(-E 2, T T) \\
& Y T=Y *(E / T T * * 2) \\
& Z T=Z *(E 2, T T * * 2)
\end{aligned}
$$


C

$$
\begin{aligned}
& P D(1,5)=-2.0 * W 1+W 3 * C C * Y T \\
& P D(1,6)=W 3 * Y \\
& P D(1,9)=2.0 * W 1 \\
& \mathrm{PD}(3,3)=(\text { WO } * Y T * C C-W 6 * \text { WL } * \text { ZT * FF) * TT } \\
& + \text { Wg } * Y * C C-W 6 * \text { WW } * Z * F F \\
& P D(3,4)=\text { WO } * Y * T T \\
& \mathrm{PD}(3.5)=W 6 * \text { Wh } * Z * \mathrm{TT} \\
& \mathrm{PD}(3,6)=W 6 * \mathrm{FF} * Z * \mathrm{TT} \\
& P D(4,2)=A 2 * 2 T * \text { W } \\
& P D(4,5)=-A 2 * Z
\end{aligned}
$$

C**********************************************

$\begin{array}{lll}\text { C } & & \\ \mathrm{C} & \text { NON-BOUNDARY PARTIRLS. } & * \\ \mathrm{C} & *\end{array}$

[*********************************************

DO $200 \mathrm{JT}=5, \mathrm{~N}-7,4$

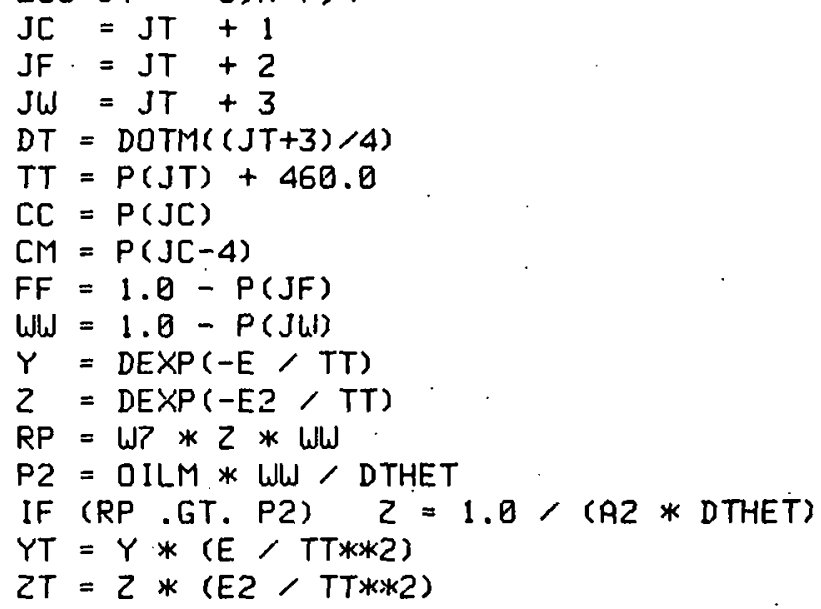

C

$P D(J T, 1)=W 1-W 2 * D T$

$P D(J T, 5)=-2.0 * W_{1}+W 3 * C C * Y T$

$P D(J T, 6)=W 3 * Y$

C

$P D(J T, 9)=W 1+W 2 * D T$

C

$P D(J C, 1)=-W 4 * D T * T T$

$\mathrm{PD}(\mathrm{JC}, 4)=(\mathrm{W5} * \mathrm{CC} * \mathrm{YT}+\mathrm{W6} * \mathrm{WW} * \mathrm{ZT} * \mathrm{~T}$ C $) * \mathrm{TT}$

+ W4 * (CC - CM) *.DT + W5*CC*Y + CC * RP / WB

$P D(J C, 5)=(W 4 * D T+W 5 * Y+W 6 * Z * W W) * T T$

$P D(J C, 7)=-W 6 * C C * Z * T T$

C $P D(J F, 1)=-W 4 * D T * T T$

$\mathrm{PD}(\mathrm{JF}, 3)=(\mathrm{WB} * Y \mathrm{~T} * \mathrm{CC}-\mathrm{W \sigma} *$ WLل $* \mathrm{ZT} * \mathrm{FF}) * \mathrm{TT}$

$\cdot$ + WO $*$ Y * CC - W6 * WW $* Z * \mathrm{ZF}$

$P D(J F, 4)=W \theta * Y * T T$

$P D(J F, 5)=(W 4 * D T+W 6 * W W * Z) * T T$

C

$P D(J F, 6)=W 6 * Z * F F * T T$

$P D(J W, 2)=A 2 * Z T * W W$

$P D(J W, 5)=-A 2 * Z$

200 CONTINUE

C*************;***************;*********;********************

C

C PRRTIALS AT UPPER BOUNDARY. $\quad *$

C

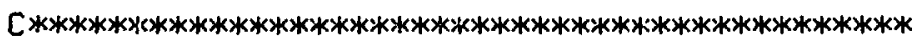




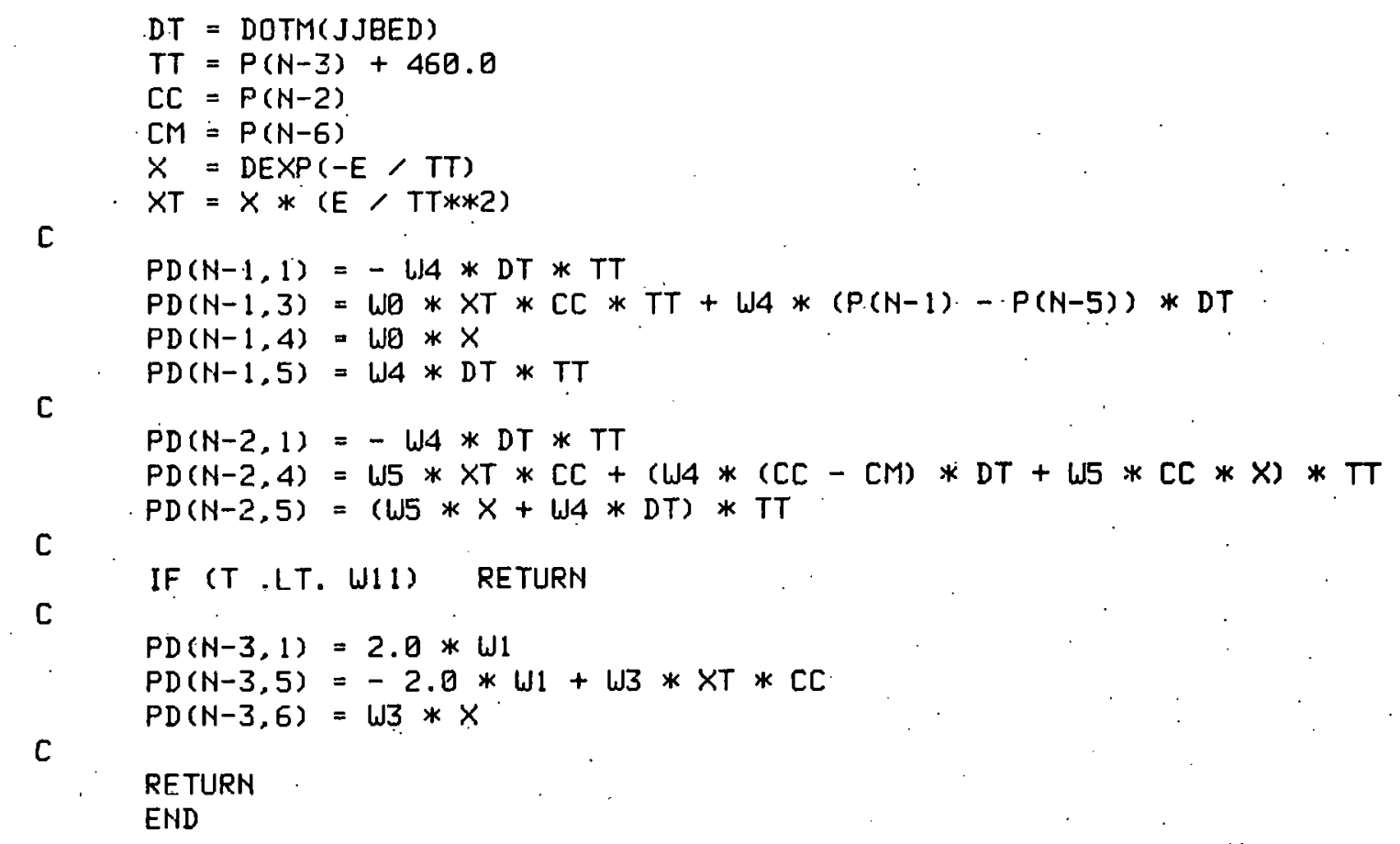


APPENDIX C

A Sample Computer Printout 


\begin{tabular}{|c|c|c|}
\hline $\begin{array}{l}\text { LE } \\
\text { PHIG } \\
\text { SAMAMC }\end{array}$ & & $\begin{array}{r}.245000 \\
.260000 \\
35.000000\end{array}$ \\
\hline H & & 5550.000000 \\
\hline & $=$ & .2 \\
\hline 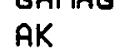 & $=$ & .3 \\
\hline & & 30. \\
\hline & & 2500. \\
\hline & & 960000. \\
\hline 22 & & 1000.08 \\
\hline 42 & & 19400000000.00 \\
\hline AMAG2 & & \\
\hline & & \\
\hline LM & & 5.5 \\
\hline FEET & & 4.08 \\
\hline & & 20.8 \\
\hline DTHET & & .10 \\
\hline W11 & & 1.08 \\
\hline & & .05 \\
\hline & & \\
\hline
\end{tabular}


TEMPERATURE

79.000090

79.000000

70.000000

79.000000

70.000000

70.000000

70.000000

70.000000

70.000000

>0. 000000

70.000000

78.000080

70.000000

P0. 000000

70.000000

70.000000

OXYGEN CONCENTRATION

1.

1. 000000

1.000000

1.000000

1.000000

1. 000000

1.000000

1.000000

1. 000000

1. 000000

1.000000

1.000000

1.000000

1.000000

1. 000000

OIL CONCENTRATION

.000000

.000000

.000000

.000000

.000000

.000000

.000000

.000000

لائlاJ

.000000

.000000

.000000

.000000

.000000

.000000

.000000

000000

LAST DOTM -.-

SUMO IL
. 00000

70.000000

70.000000

70.000000

70.000000

70.800000

70.000000

1.000000

1. 000000

1.000000

1.000000

1.000000

1.000000

1.000000

1.000000

.000000

.000000

.000000

. 000000

.000000

.000000

.000000

.000000

.000000

.000000

.000000

.000000

.000000

.000000

$.000000 \quad .000000$

.000000

2.307000000

.000000000
70.000000
70.000000

70.000000

70.000000

70.000000

70.000000

70.000000

70.000000

70.000000

1.000000

1. 000000

1.000000

1.000000

1.000000

1.000000

1.00009

1. 000000

.000000

.900000

.000000

. 90000

.000000

- 000000

900000

.090000

.090000

.000000

.000000

.000000

.090000

.000000

.000000

.000000
70.999098

70.000000

70.000000

79.900000

70.000000

70.000000

70.000000

70.000000

1.000000

1.000000

1.000000

1.000000

1.000000

1.000000

1.000000

1. 000000

.000000

.000000

.000000

000000

.000000

. 000000

000000

.000000

.000000

.000000

.000000

000000

.020000

.000000

000000

.000000
70.000000

70.000000

?.0.000000

70.000000

70.000000

70.000000

70.000000

70.090000

1.000000

1.000000

1.000000

1.000000

1.000000

1.000000

1.

1.000000

.000000

.000000

.000000

.000000

.000000

.000000

.000000

.000000

$.00000 a$

.000000

.000000

.000000

.000000

.000000

- 000000

.800000
70.000000

70.000000

70.000000

70.000000

70.000000

70.000000

70.000000

79.000000

1.000000

1.000000

1.000000

1.000000

1.000000

1.000000

1.000000

1.000000

.000000

.000000

.000000

000000

.000000

.000000

.000000

.000000

.000000

.000000

.000000

.000000

.000000

.000000

000日00

.000000
70.000000

70.000000

70.000000

70.000000

70.000000

70.000000

70.000000

ว0.000000

1.000000

1.000000

1.000000

1.000000

1.000000

1.000000

1.

1.000000

.000000

.000000

.000000

.000000

.000000

.000000

.090000

.000000

.000000

.000000

.000000

.000000

.000000

. BQEBER

.000000

.000080

70.000000

70.000000

70.000000

70.000000

70.000000

70.000000

70.000000

70.000000

1.000000

1.000000

1.000000

1.000000

1.000000

1.000000

1.000000

1.000000

.000000

.000000

.000000

000000

.000000

.000000

000000

.000000

.000000

.000000

.000000

.000000 
TEMPERATURE

70.016419

70.014899

70. E22720

70.244807

74.345681

133. 188575

707.134750

743.315636

OXYGEN BONCENTRATION

$\begin{array}{cc}1.000000 & 1.000000 \\ 1.000000 & 1.000000 \\ 1.000000 & 1.000000 \\ 1.000000 & 1.000000 \\ 1.000000 & 1.000000 \\ 1.000000 & 1.000000 \\ .2 \angle 6352 & .095443 \\ .000014 & .000005\end{array}$

OIL CONCENTRATION

-.00J000 .000000

$.003000 \quad .000000$

$.00 .3000 \quad .000000$

$.000000 \quad .000000$

.000000 .000000

$.000000 \quad .000000$

$.006338 \quad .048971$

Juld

$.138897 \quad .138897$

.00 .0000 .000000

$.00 E 000 \quad .000000$

$.008000 \quad .000000$

$.000000 \quad .000000$

$.000300 \quad .000000$

$.000300 \quad .000000$

.109219

.998891

LAST DOTM ----

SUMOIL
.332234

.999510

2. 897391318

3.491397117
70.015968

70.014956

70.031241

70.459684

77.538223

175.976426

758.432277

768.461214

\subsection{0}

1.000000

1. 000000

1.000000

1.000000

1.000000

.034854

.000002

.000000

.000000

.000000

.000000

.000000

.000000

.089331

.138865

.000000

.000000

.000000

.000000

.000000

.000000

.592264

.999790
70.015765

70.015091

70.038150

70. 589133

79.895924

207.051439

764.275844

1.000000

1.000000

1.000000

1.000000

1.000000

.999632

.012776

.000001

.000000

.000000

.000000

.000000

.000000

.000001

.114214

.138820

.080000

.000000

.000000

.000000

.000000

.000000

.782059

.999906
70.015578

70.015330

70.047712

70.788478

82.964393

247.033015

766.514092

768.603511

\begin{abstract}
1.000000
1.000000

1.000000

1.000000

1. 000000

.998557

.004744

.000000

.000000

.000000

.000000

.000000

.000000

.000107

.127222

.138770

.000008

.000000

.000000

.000000

.000000

.000000

.891326

.999959
\end{abstract}

70.015409

70.015714

70.060890

71.053561

.86 .951320

298.338522

757.396855

768.661280

1.000000

1.000000

1.000000

1.000000

1.000000

.994980

.001778

.000000

.000000

.008000

.000000

.000000

.000000

.000019

.133562

.138720

.000000

00000

.000000

.000000

.000 E0

.000000

.947948

.999997
70.015258

70.016299

70.078976

71.405024

92.123871

363.732407

767.775691

768.708264

1.000000

1.000000

1.000000

1.000000

1.000000

.981918

.000670

.000000

.000000

00000

.000000

.000000

.000000

$-.000390$

.136568

.138671

.000000

.000000

.000000

.008000

.000000

.000002

.975261

.999990
79.015128

70.017160

70.103701

71.869706

98.825588

445.435386

767.969446

768.743171

1.000000

1.000000

1.000000

1.000000

1.000000

.934222

.000253

.000000

.000000

.

.000000

.000000

.000000

$-.001072$

.137961

.138624

.000000

.000000

.000000

.000000

.000009

.000051

.988305

1.000000
70.015021

70.018409

70.13737

72.482430

107.498124

541.449931

758.096358

768.764849

1.000000

1.000000

1.000000

1.000000

1. 00090

.790416

.000096

.000000

.000000

.

000000

.000000

$-.001479$

.138576

.138579

.000000

.

.000000

.000000

900000

001170

.994587

1.000000

70.014942

70.020193

70.183052

73.288307

118.709190

637.199479

768.199146

768.772325

1.000000

1.000000

1.000000

1.000000

1.000000

.517529 
*N*N*** . 049

\subsection{4}

70.507099

76.443613

151.964697

740.660374

767.386945

767.630806

767.931433

OXYGEN CONCENTRA

$$
\begin{aligned}
& 1.000000 \quad 1.00000 \\
& 1.000000
\end{aligned}
$$

1.000000

1.000000

$1.000000 \quad 1.000000$

$1.000000 \quad .999999$

.103662 .038085

$.000006 \quad .000002$

$.000000 \quad .000000$

00000

.000000

OIL CONCENTRATION

-.000000 .000000

.000000

.000000

.000000

.046834

.142893

.142993

JWW

.143005

.000000

.000000

.000000

.080008

.312147

.999245

1.000000

1.000000

LAST DOTM ----

SUMOIL

2

- ingob

.000000

.000000

.988058

.142940

.142994

.

.000000

.000000

.999639

1.000000

1.000000
32020.000000000

PQ.101115

70.838028

70.113746

70.132913

70.159998

71.393046

87.853728

83.841618

80.729339

206.094904

245.284746

765.727689

295.556345

766.667716

767.433488

$767 . .721448$

767.477464

767.752632

767.980849

768.002286

\subsection{0}

1. 000000

1.000000

.999639

014009

.000001

.000000

.000000

.000000

.000000

.000000

1454

114541

.142963

.142995

.143008

.000000

.000000

000000

.000008

.763509

.999823

1.000000

1.000000

2.899777724

ᄀ. 902297676
1.000000

1.000000

1.000000

.998612

.005221

.000000

.000000

.000000

.000000

.000000

.000000

$-.000105$

.128848

.142975

.142997

.143009

.000000

.000000

.000000

.000000

878973

.999917

1.000000

1.000000
71.797738

359.634909

767.041766

767.500173

767.783886

768.037146

1.000000

1.000000

1.000000

.983141

.000744

.000000

.000000

.000000

.000000

.000000

.000000

$-.000321$

. 136078

.142981

.142998

.143010

.000000

.000000

.000000

.000000

940117

.999961

1.000000

1.000000

.000000

. 000000

.000000

$-.001144$

.139624

.142985

.142999

.143012

.000000

.000000

.000000

.000002

.971025

.999982

1.000000

1.000000
93.025087
70.196901

72.320604

99.689774

439.790604

767.201610

767.523873

767.814941

768.050009
1.000000

1.000000

1.000000

.939090

000283

000000

.000000

.000000

70.246164

72.995836

188.277973

534.478868

767.279944

767.548761

767.845516

768.059482

1.000000

1.000000

1. 000000

.804444

.000108

.000000

.000000

000000

.000000

. 080000

.000000

$-.004137$

.141351

.142987

.143000

.143013

.000000

000090

.000046

985992

1.000000

.999999

.000000

.000008

.000000

$-.011752$

142193

.142989

.143002

.143014

.000000

0000日0

.008000

.001061

993203

.999996

1.080000

1.000000
70.311140

73.867499

119.343576

630.356076

767.326477

767.574908

767.875322

768.065330

1.000000

1.000000

1. 000000

.539747

.000041

.000000

.000000

.000000

.000000

.000000

000000

$-.015261$

.142601

.142990

.143003

.143015

.000000

.

.080000

70.396217

74.992372

133.599724

702.360591

767.359773

767.602289

767.904062

768.067340

1.000000

. 000000

1.000000

.000016

.000000

- 000000

.000000 